\title{
Pre-emptive product patentability declarations
}

\author{
Lorna Brazell*,1 \\ 'One London Wall, London EC2Y 5EP, UK \\ * Author for correspondence: Iorna.brazell@osborneclarke.com
}

First draft submitted: 6 June 2017; Accepted for publication: 14 June 2017; Published online: 18 August 2017

Keywords: generic launch strategy $\bullet$ intellectual property $\bullet$ portfolio management $\bullet$ product life cycle

\section{What is the problem?}

Successful pharmaceutical products are typically protected by a number of patents (as well, potentially as other intellectual property) directed toward specific aspects. Frequently, a product is initially patented in the form in which it was originally launched but then later modifications and improvements are also the subject of further patent applications. As readers will undoubtedly appreciate, prosecution of patent applications (whether for a new chemical entity or, as here, secondary applications of a drug) can take years to reach grant or rejection. Even then, European Opposition or US inter partes review proceedings may be brought, thereby extending the uncertainty as to the final form of claims. In consequence, potential producers of related products face a nearly impossible task in attempting to determine whether their own version will or will not infringe some yet-to-be examined application. Launching a product carries the uncomfortable risk that amendments to the claims of a pending application may result in the new product infringing.

AbbVie Biotechnology Ltd's (Bermuda) patent strategy to maintain exclusivity over Humira ${ }^{\circledR}$ led to difficulties of this kind for Fujifilm Kyowa Biologics Co. Ltd (Japan), which was proposing to launch a biosimilar product. AbbVie's Humira is the highest-selling prescription drug in the world by global sales. Worldwide, sales in 2014 exceeded \$12.5 billion. It is used to treat, among other things, rheumatoid arthritis, psoriatic arthritis and psoriasis. There is a clear and obvious incentive for AbbVie to try to retain market exclusivity for as long as possible; not merely the 20 year lifespan of an ordinary patent.

As one would expect, AbbVie has a wide-ranging patent portfolio relating to Humira. The Supplementary Protection Certificate to the basic product patent will expire in 2018; but among other developments, AbbVie has applied for a number of European patents to particular dosage regimens for the use of Humira to treat various inflammatory diseases, including EP 1406656.

\section{What kind of relief can the courts give?}

Traditional legal approaches have struggled to provide any adequate mechanism for addressing the uncertainty caused by pending applications and opposed patents. But over time, the English courts have been developing alternatives. Both under the common law and the powers conferred by the Senior Courts Act 1981, they have a wide discretion as to the forms of order which they can grant in any commercial dispute. In fact, provided that there is a genuine commercial dispute, it would almost not be putting it too high to say that any justiciable question can be the subject of English court proceedings. These are not limited to statements as to a party's positive legal rights. The appeal courts' views were summarized by Lord Woolf in 2000 in Messier Dowty v Sabena [1]: the court could, and should not be reluctant to grant negative declarations where it would serve a useful purpose and help to ensure that the aims of justice are achieved.

In recent years, this flexibility has led to the development of new options in the field of patent disputes, alongside the traditional statutory remedies of applications to revoke, claims for infringement and declarations of invalidity of a patent (section 74 Patents Act 1977) or noninfringement by a particular product (section 71). The courts have been prepared to rule on whether a patented technology is essential to a technical standard, or whether a particular 
set of terms for licensing a patent comply with the criteria of fairness, reasonableness and nondiscrimination (Unwired Planet $v$ Huawei). New negative remedies include declarations of nonessentiality (again in the context of disputes over standard-essential patents such as Nokia $v$ InterDigital [3]), which have enabled a short-circuiting of the usual in-depth technical analysis of a complex electronic product by instead comparing an asserted patent against the standard to which it has been declared essential.

However, the courts are not prepared to grant a declaration that a patent, if granted, would be invalid as this would usurp the role of the relevant patent office in considering the application.

Fujifilm's solution was to apply for an 'Arrow' declaration. This form of order, named after the case of Arrow Generics $v$ Merck [4] in which it was first considered, enables a business to cut through the uncertainties of a portfolio of pending applications or patents under opposition and seek a declaration that the product which it proposes to launch cannot be the subject of any valid grant of a patent because it is itself either not novel, in the light of specific cited prior art, or lacks inventive step. The consequence of such a declaration is that, if the drug's originator succeeds in obtaining the grant of a patent which covers the applicant's product, then that patent must necessarily be invalid since the infringing product is unpatentable. The patentee is therefore squeezed into an unwinnable position; equivalent to the argument in infringement proceedings (known as a Gillette defense) that the defendant's product implements prior art technology, such that any patent which it infringes must be invalid.

In Fujifilm Kyowa Biologics v Abbvie Biotechnology [5], the Court of Appeal upheld the High Court's ruling that such declarations are, indeed, within the scope of the English court's discretion in appropriate cases. No such authoritative ruling had been made in the Arrow case itself since it settled before trial.

\section{When can an Arrow declaration be obtained?}

Applying for such a declaration requires a similar level of preparation to applying for a declaration of noninfringement combined with a validity attack. The applicant needs to:

- Set out all relevant aspects of the proposed product;

- Identify the date at which novelty and obviousness are to be assessed;

- Identify the state of the art at that date to enable the comparison to be drawn.

It further needs to establish that there is a genuine commercial controversy, since the English courts are not in the business of deciding hypothetical questions: the discretion to grant relief can only be exercised where to do so serves a useful purpose. In the pharmaceutical field, establishing such a controversy does not necessarily entail a high burden of evidence since the English courts already require a generic company proposing to launch 'at risk' of patent infringement proceedings to 'clear the way' before launch by bringing revocation actions in respect of any potentially problematic patents. Such actions are routinely brought and decided without the patentee having made any initial motion toward an infringement action - as, indeed, it normally cannot when the generic has not yet launched a product. But in this context, if the originator is making significant profits from the product family, and is continuing to diversify and patent around it, and is asked to confirm whether it will seek to enforce any granted or pending patents against a competing product, then it is going to have to make clear and express statements about its intentions or risk the court drawing its own conclusion. The court is very likely to conclude that making a declaration will indeed be useful; the threshold for which is only that it be "more use than shouting into an empty room".

In this case, AbbVie's CEO had made various public statements expressing AbbVie's intention and threat to block biosimilars of Humira through its patent portfolio, and that these threats applied to European commercial activity. The English court is very much alive to the commercial risk that the threat of long-running patent disputes can give rise to. For example, in contrast to some other jurisdictions, an English patent dispute will not necessarily be stayed thus pending the outcome of parallel opposition proceedings at the European Patent Office (EPO); even though the EPO ruling will be ultimately determinative of the issues. When the correctness of this approach was questioned by the Supreme Court, the Court of Appeal explained in a dispute between IPCom and HTC [6] that the court is entitled to refuse a stay of the national proceedings where the evidence is that some commercial certainty would be achieved at a considerably earlier date in the case of the UK proceedings than in the EPO. It took the view that some commercial certainty, rather sooner than later, and somewhere such as in the UK, rather than nowhere, is in general, preferable to continuing in uncertainty everywhere, even if there is likely to be an increase in total litigation costs and an unavoidable risk of inconsistent rulings by the two tribunals. In practice, it can almost be 
sufficient to establish that commercial risk exists that, when put on notice of a possible launch, the patentee has refused to give an unconditional green light.

AbbVie nevertheless attempted to undermine the existence of any such useful purpose by offering an undertaking to the court not to obtain future patent protection in the UK for the relevant dosage regimen. It also offered to pay Fujifilm's costs of the proceedings if that proposal was accepted. As a result, they said, the way had been cleared in the UK because all relevant patents had been abandoned or de-designated, and their undertaking had been offered. But Fujifilm rejected the offer and instead asked Abbvie to submit to the declaration it had requested. Abbvie's refusal supported the proposition that the declaration did, indeed, still have a useful purpose - presumably, the potential persuasive value that the judgment might have in other jurisdictions, should Abbvie sue elsewhere.

In addition, there may need to be some grounds to argue that the patent applicant is conducting itself so as to shield the subject matter of the application from scrutiny in the national court, whether or not that is its subjective intention. In the absence of such conduct, the normal remedies available expressly under the Patents Act 1977 to challenge validity once the patent has been granted, or apply for a declaration of noninfringement - should be sufficient protection for the applicant. In Fujifilm v Abbvie, Fujifilm pointed to the fact that Abbvie had caused its recently granted EP-1406656 to be revoked by the EPO, notwithstanding that it had recently filed responses to various oppositions accompanied by no fewer than 19 statements of fact and expert opinions, at considerable cost in time and effort. This curious decision suggested that until Fujifilm's UK claim for revocation and a declaration was filed, Abbvie had held every intention of defending the granted patent tooth and nail.

At trial, the court considered the technical issues, which came down to whether or not the administration of Fujifilm's proposed products at a particular dose of $40 \mathrm{mg}$ by subcutaneous injection, every other week for the treatment of rheumatoid arthritis, was inventive at the priority date. On the basis of the prior art and expert evidence, the judge held that it was not. In the circumstances (including the sums of money at stake) it was appropriate to make the declaration.

\section{Finding the right balance}

However, it is important to not frame the request for a declaration too broadly. As mentioned above, the court is unlikely to be prepared to declare that the pending European patent applications cannot mature into the grant of valid patents of any form. Nor is the court interested in granting declarations in respect of hypothetical products, though for instance, it should be possible to obtain a declaration that generic versions of existing marketed presentations of the same active ingredient are not patentable. However, an application seeking protection for the possible outputs of a research project, encompassing a range of possible but not yet defined products, will not succeed.

Nor will the grant of such a declaration assist a company whose eventual marketed product does not fall within the description relied upon by the court. Accordingly, such applications can most effectively be filed only in the immediate prelaunch period, where the product is in final form such that a marketing authorization application has been or is about to be submitted.

Nevertheless, for companies which can meet the necessary conditions, and are otherwise facing the prolonged commercial uncertainty given rise by a sophisticated competitor's patenting strategy, the opportunity to apply for a declaration in the Arrow form can provide a very valuable way through, and to market in at least the UK, well before the EPO completes its deliberations. Following the 2007 English decision of principle in Arrow, the Dutch court has also been prepared to grant similar declarations in a 2008 case over specific dosage alendronate tablets for treating osteoporosis between Merck and Ratiopharm.

Financial \& competing interests disclosure

The author has no relevant affiliations or financial involvement with any organization or entity with a financial interest in or financial conflict with the subject matter or materials discussed in the manuscript. This includes employment, consultancies, honoraria, stock ownership or options, expert testimony, grants or patents received or pending, or royalties.

No writing assistance was utilized in the production of this manuscript.

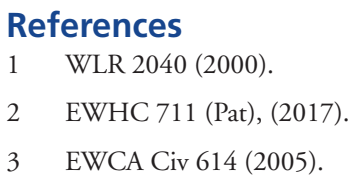


Editorial Brazell

4 EWHC 1900 (Pat), (2007), FSR 39 (2007), Bus LR 487 (2008).

5 EWCA Civ 1 (2017).

6 EWCA Civ 1496, (2014), RPC 12 (2013). 